\title{
The sounds of silence: Public goods, externalities, and the value of infectious disease control programs
}

\author{
David N Fisman MD MPH FRCPC ${ }^{1}$, Kevin B Laupland MD MS FRCPC ${ }^{2}$
}

$\mathrm{P}$ rofessionals who devote their careers to the control of communicable diseases, whether in the community or hospital setting, are assured an endless and varied series of challenges due to the dynamic nature of microbial populations, the mobility of human populations, and technological changes that facilitate the emergence, identification and quantification of emerging infectious disease threats. However, many practitioners working in hospital epidemiology or public health have experienced the following frustration: the incidence of an infectious process has been reduced or eliminated through application of a successful control program (eg, the introduction of vaccination or active surveillance for carriage of antimicrobial resistant pathogens). As the threat of the disease in question (whether measles or infection with health careassociated methicillin-resistant Staphylococcus aureus [MRSA]) declines, administrators or program participants question the necessity of the program, with subsequent erosion of resources and support.

The opposite may occur: elimination of disease surveillance programs or case-finding efforts may result in an apparent decline in disease incidence, with a resultant pat on the back from administrators for a job well done. A number of examples of this phenomenon, drawn from recent newspaper headlines, come to mind. In Ontario, the legal requirement that cheeses be pasteurized (a health measure that has been successful in diminishing serious foodborne illness) has been criticized, even in the face of contradictory calls for 'enhanced food safety' following the province's role in the recent pan-Canadian listeriosis outbreak $(1,2)$. Resurgences have been identified in historically well-controlled vaccine-preventable diseases, including rubella, measles, mumps and pertussis in the face of increasing popular concern that the risks of vaccination do not outweigh the benefits when disease is uncommon (3). Perhaps the most poignant example of this phenomenon involves an Ontario health ministry spokesperson who, a year before severe acute respiratory syndrome (SARS) exposed gaps in that province's public health capacity, justified cuts to the province's public health laboratory as follows: "Do we want five people sitting around waiting for work to arrive? It would be highly unlikely that we would find a new organism in Ontario" (4).

Complicating matters further, rapid growth of costs in health care (5) have resulted in demands that health programs, including those that target infectious disease prevention and control, justify their roles through demonstration of costneutrality, or even revenue generation. For example, a recent document produced by a working group of the Society for Hospital Epidemiology of America provided guidance to health care professionals on the construction of 'business cases' to justify hospital infection control budgets (6).

To summarize this paradoxical state of affairs, control of infectious diseases requires active, ongoing intervention, but disease control successes manifest as the nonoccurrence of events (ie, silence). Maintenance of such silence requires active investment, but decision-makers and the public may be reluctant to invest when 'nothing is happening'. Public health crises, including outbreaks and epidemics, result in a booster dose of interest, funding, and resources, but at a high cost (both health and monetary). We propose that the first step toward remedying this state of affairs lies in the recognition that maintenance of communicable disease control, in a jurisdiction or hospital, represents a type of 'public good'. The economic framework that has previously been created to maintain other public goods (such as urban infrastructure or clean water) may have value if applied to communicable disease control.

\section{PUBLIC GOODS AND MARKET FAILURES}

Public goods are defined by economists as goods that are nonexcludable (consumers cannot be prevented from accessing these goods) and non-rival (having additional consumers does not diminish the availability of the good to others) (7). Consider the state of affairs in a city that has applied stringent regulations to improve its air quality: the benefits associated with breathing clean air are available to anyone who visits the city. Additional visitors to the city will not diminish the benefit of clean air to those already residing there.

In a similar manner, the historical investment in drinking water and sewage treatment, food safety, vaccination and tuberculosis treatment in Canada provide a visitor or newcomer to this country with an environment in which the acquisition of a life-threatening communicable disease is less likely than it would be in many countries that have not been able to make such investments. This is freedom from communicable diseases as a public good.

This paradigm is a reasonable, although imperfect, fit for many of the paradoxical challenges we describe above. Communicable diseases are often 'density dependent' (8), in

${ }^{1}$ The Research Institute of the Hospital for Sick Children, University of Toronto, Ontario Agency for Health Protection and Promotion, Toronto, Ontario; ${ }^{2}$ Departments of Medicine, Critical Care Medicine, Pathology and Laboratory Medicine, Centre for Antimicrobial Resistance, University of Calgary, Calgary Laboratory Services, Calgary Health Region, Calgary, Alberta 
that likelihood of transmission depends on increasing number of infectious and susceptible individuals. In this sense, the presence of excellent infection control practices in a health care institution may be somewhat 'rival': overcrowding may actually diminish this good, either by increasing transmission or by overwhelming health care workers (and giving them less time for infection control practices). Acknowledging these limitations, let us discuss why public goods are of such interest to economists, and how the evaluation of communicable disease challenges through a public good lens may be helpful.

Public goods are of interest to economists because the 'trade' in such goods is likely to be attended by market failures (7). What are market failures? Traditional economic transactions involve the exchange of goods between those who seek to maximize their own happiness or utility: if I buy a basket of groceries, I get the food I need to eat, and the money I spend provides the vendor with the means to meet his or her own needs. In a medical context, there is provision of a healthgenerating service by a physician, paid for by the patient (or, in the case of Canada, a third-party insurer) at some equilibrium price set by the market for such services.

However, because it is not possible to charge individuals for the consumption of a public good, this traditional framework breaks down when applied to public goods, resulting in market failures. What if the medical service provided above is an invasive medical procedure, performed in a hospital? The patient who has this procedure performed in a hospital with an exquisite infection control program is less likely to have the procedure complicated by subsequent infection. It is not possible to restrict this benefit only to those patients who choose to pay an 'infection control surcharge'. Post hoc requests that patients whose procedures have not been complicated by infection pay for this 'additional benefit' are likely to be equally unsuccessful. Subject to the constraints of crowding described above, the benefit should not be diminished by increasing the hospital's procedure volume. Similar (and similarly absurd) examples could be envisioned for food safety, sexually transmitted disease and vaccine-preventable disease control programs.

Because market pricing fails for public goods, such goods need to be maintained by external forces, which typically take the form of external regulation and taxation. In the Canadian context, taxes do indeed fund federal, provincial and local public health services. However, in the context of block funding to health care institutions, there is no analogous system of taxation to support excellence in hospital infection control; rather, hospital infection control activities are required for maintenance of accreditation. An interesting recent approach to providing (negative) incentives for the maintenance of low rates of infection in hospitals is the decision by the United States Centers for Medicare and Medicaid Services to no longer reimburse hospitals for the excess length of stay and costs associated with adverse medical events, including hospital-acquired infections (9). However, such a system effectively deprives the worst performing hospitals of revenue that could in theory be reinvested in improving infection control practices, whereas usual fiscal approaches to the maintenance of public goods involve reinvestment of tax revenues in promotion of the good in question.

\section{EXTERNALITIES AND THE GAMES FREE RIDERS PLAY}

Public goods are often what economists refer to as externalities on transactions; these are goods that affect parties not directly involved in the transaction. This is easily conceptualized by thinking about a measles vaccination program. An individual who accepts vaccination against measles lowers his or her risk of contracting measles in the event of contacting a measles case. However, by accepting vaccination, this individual also makes it unlikely that he or she will serve as a source for future measles infection in other individuals. This future noninfectious state is an externality on the receipt of vaccination. When a 'critical fraction' of a given population accepts vaccination, the introduction of an infectious individual (for example, via air travel from a region where the disease is endemic) no longer results in a self-sustaining chain of disease transmission, and the disease is eliminated. This state of affairs is referred to as herd immunity (10), and represents an example of externalities as a public good.

Negative externalities are also possible. A hospital that pays little attention to antibiotic stewardship or infection control precautions may serve as an incubator for individuals colonized with antimicrobial-resistant organisms, and these individuals may become a source of infection for individuals elsewhere (for example, in long-term care facilities). A similar framework might be applied to overuse of antibiotics for upper respiratory infections. In the case of vaccinations that achieve herd immunity, the nature of the public good generated is such that it may actually discourage individuals from accepting vaccination: if individuals can accrue the benefits of vaccination (as a result of herd immunity) without themselves accepting the (small) risks attendant on vaccination, some will choose to do so. This is referred to as a free-ridership problem.

Indeed, as Canadian mathematicians Chris Bauch and David Earn point out, the risk calculus of a rational actor is likely to encourage such free ridership, especially if vaccines are perceived to be risky as a result of public health 'scares' (eg, the unfounded belief that vaccines elevate autism risk) (3). Bauch and Earn (3) note that game theory, a branch of economics that predicts what rational people are likely to do based on their expectations of the actions of others, predicts that disease elimination should be difficult to achieve due to free ridership. As the risk of disease becomes very low (thanks to vaccination) any risk associated with vaccination will outweigh risk of disease. The result is that vaccine coverage drops, causing disease outbreaks, and these outbreaks drive individuals to again favour vaccination. The system will reach an 'equilibrium point' where fear of disease and fear of vaccination are equally balanced. Such game theoretical models may also apply to hospital infection control: the motivation of a health care institution to institute stringent infection control policies may be curtailed if that institution expects that other institutions will fail to do so as well, such that any gains will be eroded by admission of patients who have contracted antimicrobialresistant organisms in neighboring hospitals.

\section{SEE NO EVIL, HEAR NO EVIL - MEASURE NO EVIL?}

A common problem in the evaluation of public goods relates to the measurement of these goods. For example, to use the air 
quality example above, if a jurisdiction has no reports of adverse air quality, this could either be because air quality is good, or because air quality is not being measured! To extend this analogy to communicable diseases is to emphasize the importance of high quality, comprehensive, real-time communicable disease surveillance systems for assessment of the level of communicable disease activity in a hospital or jurisdiction. Unfortunately, improved surveillance may create the impression that things are worse, not better, due to improved case finding. Decision-makers may resist the push for better surveillance, on the assumption that identifying more (otherwise silent) disease will reflect poorly on existing disease control activities (a concept familiar to economists as 'moral hazard').

Several salient examples of this phenomenon come to mind: as Chlamydia screening programs have expanded, more testing has been performed, and this may be an important determinant of apparently increasing rates of Chlamydia infection. Nonetheless, rising rates in the face of expanded Chlamydia screening activities have been cited as evidence of the ineffectiveness of screening (11). The rapid identification of the recent emergence of a novel H1N1 influenza strain in North America represents a major success for public health surveillance; nonetheless, this success has been criticized because, to quote the New York Times, surveillance systems may have been "too sensitive, alerting the world to a virus no more dangerous than the usual seasonal flu bugs" (12). However, insensitive surveillance systems may foster events that cannot be ignored. For example, an insensitive case definition (that required individuals to have contact with a known SARS case to be designated

\section{REFERENCES}

1. Attaran A, MacDonald N, Stanbrook MB, et al. Listeriosis is the least of it. CMAJ 2008;179:739-40, 743-4.

2. Oliveira M. Raw milk crusader returns to court to fight charges. Globe and Mail, Toronto, 2009. <www.theglobeandmail.com/servlet/ story/RTGAM.20090125.wrawmilk0125/BNStory/ specialScienceandHealth/> (Version current May 2, 2009).

3. Bauch CT, Earn DJ. Vaccination and the theory of games. Proc Natl Acad Sci U S A 2004;101:13391-4.

4. Abraham C, Priest L. Cost-cutting measures fueled SARS spread. Globe and Mail, Toronto, 2003. <www.theglobeandmail.com/servlet/ story/RTGAM.20030502.wxsars0503/BNStory/Front/>. (Version current May 2, 2009).

5. MacKinnon JC. The arithmetic of health care. CMAJ 2004;171:603-4.

6. Perencevich EN, Stone PW, Wright SB, Carmeli Y, Fisman DN, Cosgrove SE. Raising standards while watching the bottom line: Making a business case for infection control. Infect Control Hosp Epidemiol 2007;28:1121-33. a SARS case), was revised only after the onset of Toronto's second wave of SARS cases in May 2003 (13).

\section{INFECTIOUS DISEASE CONTROL AS A PUBLIC GOOD: IMPLICATIONS FOR HEALTH POLICY}

In summary, the absence of infectious disease in a community or health care setting is a public good, and as with other public goods, does not 'just happen'. Disease control efforts require active investment and effort, as well as ongoing monitoring in the form of high-quality surveillance systems. Such systems must be sufficiently stable over time to distinguish artifactual surges in disease due to improved case finding from true increases in disease incidence. The importance of recognizing the applicability of this paradigm to disease control programs relates to the problem of free ridership by those who enjoy these public goods, and the importance of some form of redistribution of wealth (eg, funding of strong infection control programs via tithes on hospital programs that benefit from their presence) to sustain these goods. Infection control programs should not have to justify their existence by building business cases!

We would also suggest that the magnitude of the public good created by those who have studied and fought infectious diseases over the past century are best understood by those with a knowledge of the history of medicine and public health. We have many current and future challenges as a disease control community, but we also have ample reason to be proud of the great but silent good we have created.

7. Sandler T. Economic Concepts for the Social Sciences, 1st edn. New York: Cambridge University Press, 2001.

8. Anderson R, May R. Infectious Diseases of Humans, 1st edn. Oxford: Oxford University Press, 1992.

9. Pronovost PJ, Goeschel CA, Wachter RM. The wisdom and justice of not paying for "preventable complications". JAMA 2008;299:2197-9.

10. Edmunds WJ, Medley GF, Nokes DJ. Evaluating the cost-effectiveness of vaccination programmes: A dynamic perspective. Stat Med 1999;18:3263-82.

11. Low N. Screening programmes for chlamydial infection: When will we ever learn? BMJ 2007;334:725-8.

12. Harris G. Questions Linger Over the Value of a Global Illness Surveillance System. New York Times, New York, 2009. <www. nytimes.com/2009/05/02/health/02global.html> (Version current May 2, 2009).

13. Naylor D, Basrur S, Bergeron M, et al. SARS in Canada: The anatomy of an outbreak. In: Learning from SARS: Renewal of Public Health in Canada. Ottawa: Publications Health Canada, 2003:23-42. 


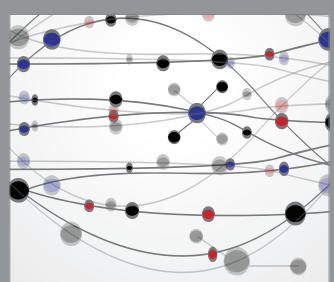

The Scientific World Journal
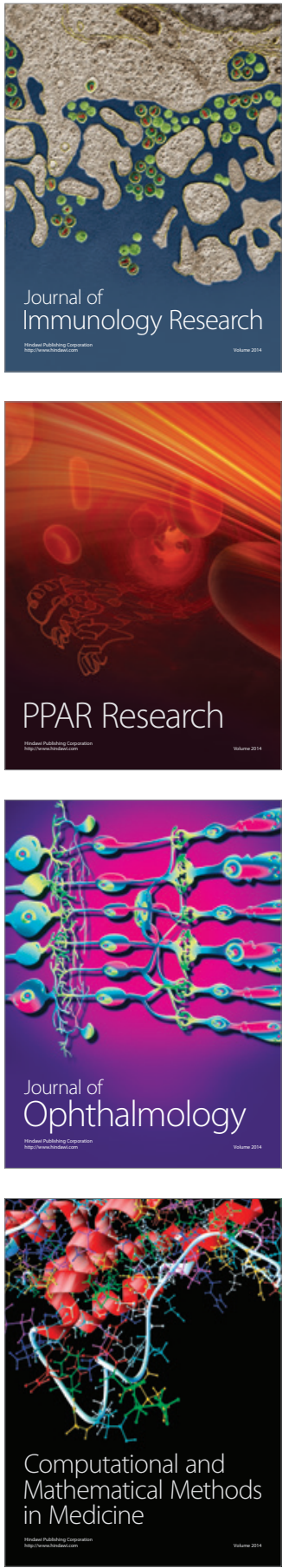

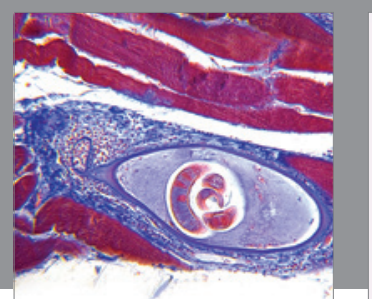

Gastroenterology Research and Practice

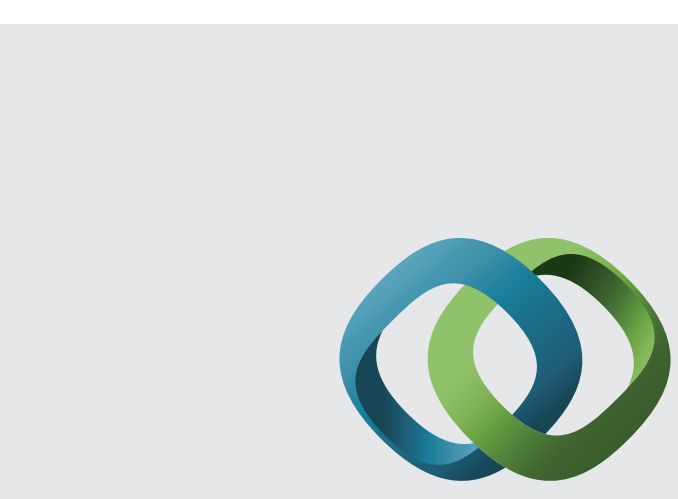

\section{Hindawi}

Submit your manuscripts at

http://www.hindawi.com
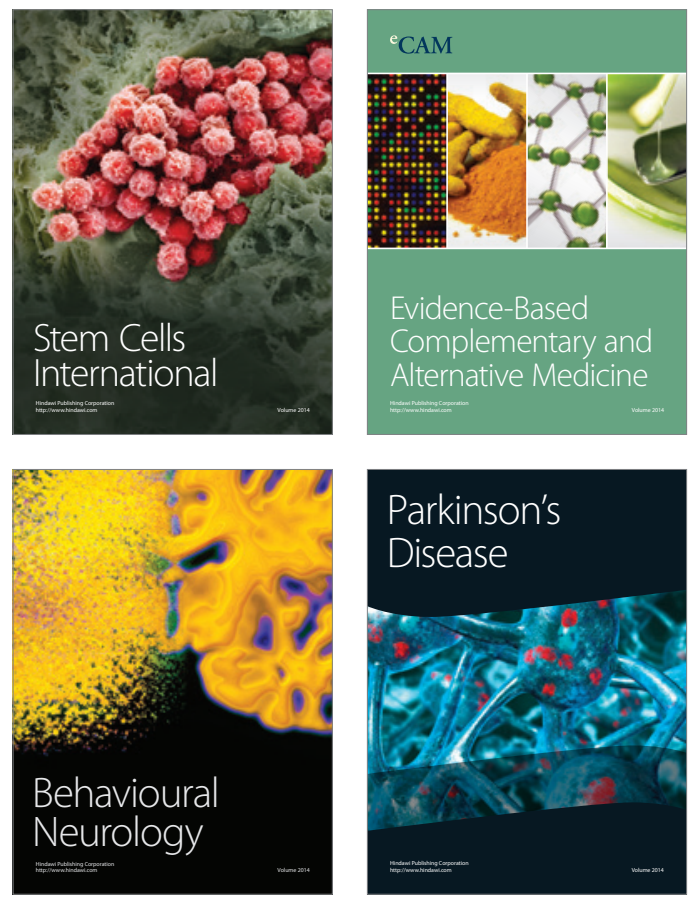
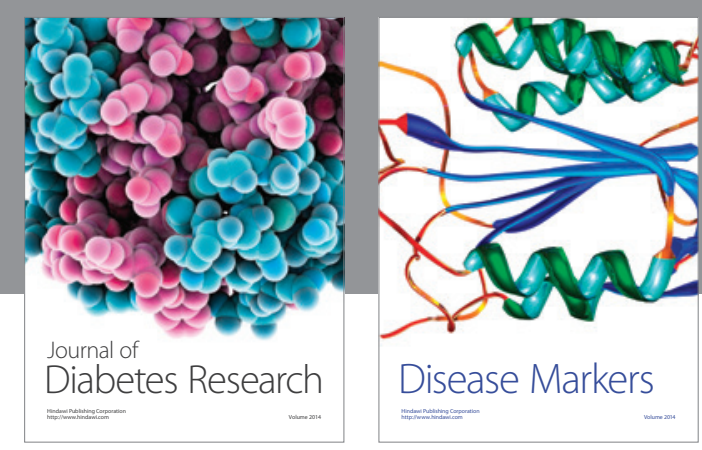

Disease Markers
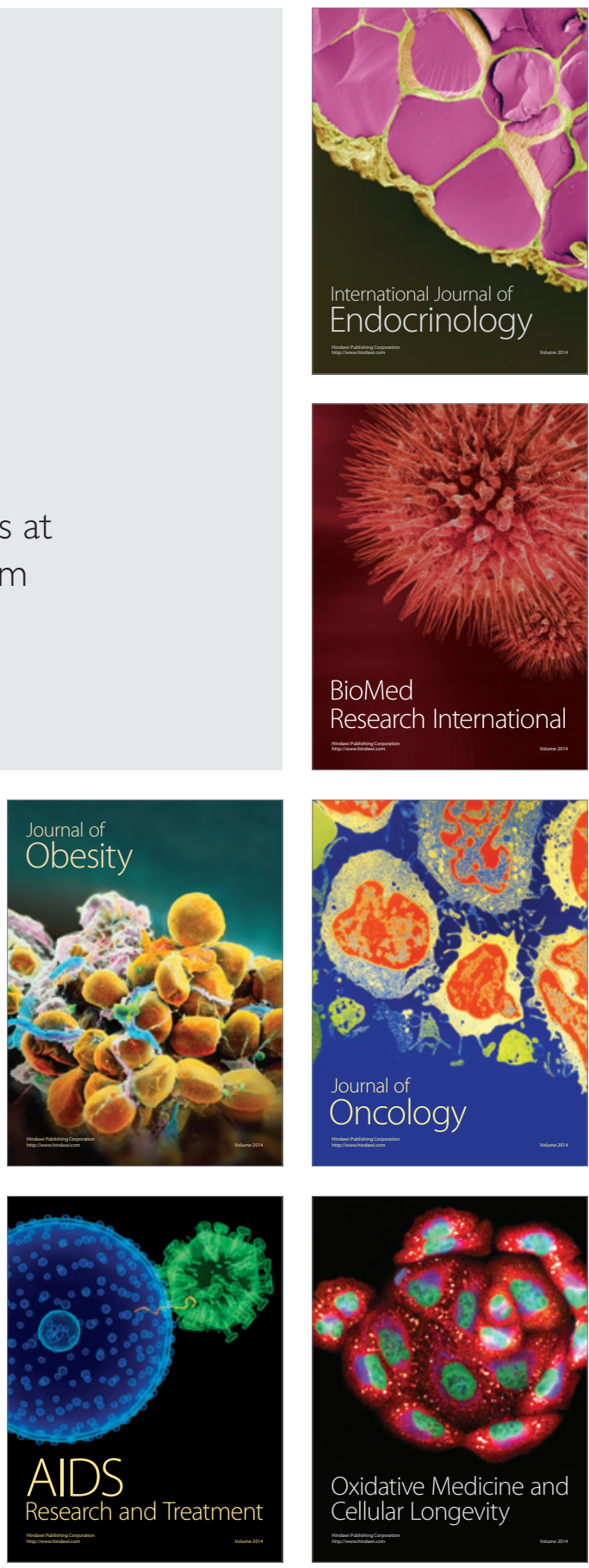